\title{
Histopathological Outcomes of Women with Abnormal Cervical Cytology: a Review of Literature in Thailand
}

\author{
Chumnan Kietpeerakool $^{1 *}$, Siriwan Tangjitgamol ${ }^{2}$, Jatupol Srisomboon ${ }^{3}$
}

\begin{abstract}
Cervical cytology remains the principal screening method to detect pre-invasive and invasive cervical lesions. Management of abnormal cervical cytology depends on the risk of encountering a significant cervical lesion or high-grade cervical disease. These risks may vary in different areas across the country. Thus, determining the rate of significant cervical lesion associated with each type of abnormal cervical cytology in each area is of critical importance for designing area-specific management approach. This review was conducted to evaluate the rate of high-grade cervical disease among Thai women with abnormal cervical cytology. A relatively high incidence of underlying significant lesions including invasive disease was demonstrated even in those having only minimal smear abnormality. This baseline information is crucial and must be taken into consideration in management of women with abnormal cytological screening to achieve the goals of comprehensive cervical cancer control in Thailand.
\end{abstract}

Keywords: Cervical cancer - cytology - pathology - cancer control - Thailand

Asian Pac J Cancer Prev, 15 (16), 6489-6494

\section{Introduction}

Cervical cancer remains the major health problem in Thailand and many other developing countries. This is mainly because of failure to initiate or sustain effective screening strategy. In recent population-based cancer registries, the highest incidence of cervical cancer in Thailand was noted in Chiang Mai with an average agestandardized incidence rate (ASR) of 28.9 per 100000 , followed by Lampang (ASR, 22.4) and Bangkok (ASR, 20.9) (Moore et al., 2010).

Although high-risk Human Papillomavirus (HR-HPV) test and HPV genotyping have certain role in cervical cancer screening nowadays, these tests are not widely available in developing countries. Cervical cytology is still the principal screening method. Subsequent management of abnormal cervical cytology to detect underlying cervical lesions is also important. Generally, management of abnormal cervical cytology depends on the risk of encountering high-grade cervical disease. However, the risks of high-grade cervical disease encountered in abnormal cervical cytology may vary among different regions of the world and across the country. Therefore, information regarding the incidence of significant cervical disease from different areas or populations is crucial for designing and implementing area-specific management approach. This review was conducted to evaluate the incidence of high-grade cervical diseases among Thai women with abnormal cervical cytology.

\section{Methodological Approach}

An electronic literature search was performed through PubMed, Scopus, Web of Science, and Thai database of health science journals (thailand digitaljournals. org). A systematic search strategy was developed based on a preliminary scope of studies involving cervical histopathological outcomes among Thai women with abnormal cervical smears regardless of smear technique. However, only studies that applied the 2001 Bethesda System for reporting cervical cytology were included. Search terms were formulated based on an interpretation of the population/problem of interest, intervention and context (or PICO) framework (Cooke et al., 2012). Reference lists of eligible publications were reviewed to ascertain additional relevant papers. The authors may be contacted for more information if necessary. The last update searching was performed in April, 2014. The review results were reported according to type of smear abnormality.

\section{Findings}

\section{Atypical squamous cells}

One of the fundamental revisions of the 2001 Bethesda System for reporting cervical cytology was the elimination

${ }^{1}$ Department of Obstetrics and Gynecology, Faculty of Medicine, Khon Kaen University, Khon Kaen, ${ }^{2}$ Faculty of Medicine Vajira Hospital, Navamindradhiraj University, Bangkok, ${ }^{3}$ Faculty of Medicine, Chiang Mai University, Chiang Mai, Thailand *For correspondence: kiet_ji@hotmail.com 
of atypical squamous cell of undetermined significance (ASCUS), favor reactive and ASCUS, not otherwise specified. All interpretations of ASC are qualified as "of undetermined significance" (ASC-US) or "cannot exclude high-grade squamous intraepithelial lesion" (ASC-H) (Solomon and Nayar, 2004).

\section{Atypical squamous cells of undetermined significance}

Criteria for interpretation of ASC-US include: 1) nuclei size of approximately two and one half to three times the area of the nucleus of a normal intermediate squamous cell; 2) slightly increased ratio of nuclear to cytoplasmic area; 3) minimal nuclear hyperchromasia and irregularity in chromatin distribution or nuclear shape: and 4) nuclear abnormality associated with dense orangeophilic cytoplasm, or the so-called "atypical parakeratosis" (Solomon and Nayar, 2004).

Seven previous studies from Thailand were reviewed (Table 1). Overall, the incidence of cervical intraepithelial neoplasia (CIN) 2-3/adenocarcinoma in situ (AIS) ranged from $8.0 \%$ to $18.5 \%$ (Kiatpongsan etal., 2006; Kantathavorn et al., 2008; Suntornlimsiri, 2010; Poomtavorn et al., 2011; Pothisuwan et al., 2011; Ekalaksananan et al., 2011; Kingnate et al., 2014;). These findings were in line with previous studies from North America (Levi et al., 2003; Boardman et al., 2006; Selvaggi, 2006; Sherman et al., 2006; Srodon et al., 2006; Feng and Husain, 2007; Safaeian et al., 2007 Siddiqui et al., 2008). Nevertheless, it should be noted that four studies from Thailand reported higher incidences of invasive cervical lesion than that reported among North American population: $1.7 \%$ to $7.9 \%$ (Kiatpongsan et al., 2006; Kantathavorn et al., 2008; Suntornlimsiri, 2010; Kingnate et al., 2014) vs less than $1.0 \%$ respectively (Levi et al., 2003; Boardman et al., 2006; Selvaggi, 2006; Sherman et al., 2006; Srodon et al., 2006; Feng and Husain, 2007; Safaeian et al., 2007; Siddiqui et al., 2008). As per the 2012 American Society for Colposcopy and Cervical Pathology (ASCCP) guidelines, the preferred method for managing women with ASC-US is a reflex HPV testing (Massad et al., 2013). Repeating cytology at 1-year interval is an acceptable alternative while colposcopy is not recommended as a primary investigation (Massad et al., 2013). In view of a high incidence of invasive lesion noted in some studies in Thailand, an immediate colposcopy might be needed to detect the significant lesions especially in women who were expected to have poor compliance for a follow-up. In addition, the cost of colposcopy is much lower than that in the western countries.

Atypical squamous cells, cannot exclude high-grade squamous intraepithelial lesion

Atypical squamous cells, cannot exclude highgrade squamous intraepithelial lesion (ASC-H) denotes cytological features with some, but not all, of the cytomorphologic criteria for high-grade squamous intraepithelial lesion (HSIL) (Solomon and Nayar, 2004). Immediate colposcopy is recommended for women with ASC-H cytology. Two studies on the histopathological outcomes of women with ASC-H conducted in Thailand were available for review (Table 1). In our previous report, the rate of significantly cervical lesion in women with smears revealing ASC-H was $75.0 \%$, in which $9.3 \%$ were invasive cancer (Kietpeerakool et al., 2009). In the recent study by Kingnate et al (2014), incidence of CIN 2-3/AIS and invasive lesion was $10.5 \%$ and $2.6 \%$, respectively. In the literature, almost all studies evaluating histopathologic results of ASC-H smears were reported from North America where the incidence of cervical cancer appears to be relatively low (Alli and Ali, 2003; Louro et al., 2003; Selvaggi, 2003; Liman et al., 2005; Barreth et al., 2006; Saad et al., 2006; Srodon et al., 2006; McHale et al., 2007). The rate of underlying high-grade cervical lesion varied widely from $10 \%$ to $80 \%$, in which less than $3.5 \%$ were invasive lesion (Alli and Ali, 2003; Louro et al., 2003; Selvaggi, 2003; Liman et al., 2005; Barreth et al., 2006; Saad et al., 2006; Srodon et al., 2006; McHale et al., 2007).

Because of a lax criterion for interpreting ASC-H smear, poor interobserver agreement is anticipated which might be partly attributable for the wide variation of the rate of significant cervical lesion as have been noted in either Thai or North American settings (Quddus et al., 2001; Sherman et al., 2001). However, the notably high incidence of invasive lesion demonstrated (2.6\%-9.3\%) might indicate the necessity for aggressive management in Thai women with ASC-H cytology to make certain that occult invasive lesions could be detected and treated in a timely fashion.

Table 1. Histopathological Outcome in Thai Women with Atypical Squamous Cells on Cervical Smears

\begin{tabular}{|c|c|c|c|c|c|c|}
\hline Authors & $\begin{array}{l}\text { Smear } \\
\text { type }\end{array}$ & Year & $\begin{array}{c}\text { No. } \\
\text { patients }\end{array}$ & CIN 1 or less & $\begin{array}{l}\text { rlying histopathology } \\
\text { CIN 2-3/AIS }\end{array}$ & Cancer \\
\hline & ASC-US & & & & & \\
\hline Kiatpongsan et al & & 2006 & 90 & $76(84.5)$ & $11(12.2)$ & $3(3.3)$ \\
\hline Kantathavorn et al & & 2008 & 208 & $179(86.1)$ & $24(11.5)$ & $5(2.4)$ \\
\hline Suntornlimsiri et al & & 2010 & 254 & $187(73.6)$ & $47(18.5)$ & $20(7.9)$ \\
\hline Poomtavorn et al & & 2011 & 266 & $229(86.1)$ & 37 (13.9) & $0(0)$ \\
\hline Pothisuwan et al & & 2011 & 47 & $43(91.5)$ & $4(8.5)$ & $0(0)$ \\
\hline Ekalaksananan et al & & 2011 & 112 & $103(92.0)$ & $9(8.0)$ & $0(0)$ \\
\hline Kingnate et al & & 2014 & 779 & $677(86.9)$ & 89 (11.4) & $13(1.7)$ \\
\hline & ASC-H & & & & & \\
\hline Kietpeerakool et al & & 2009 & 108 & $37(34.1)$ & $61(56.5)$ & $10(9.3)$ \\
\hline Kingnate et al & & 2014 & 152 & $132(86.8)$ & $16(10.5)$ & $4(2.6)$ \\
\hline
\end{tabular}

ASC-US, atypical squamous cells of undetermined significance; ASC-H, atypical squamous cells, cannot exclude high-grade squamous intraepithelial lesion; CIN, cervical intraepithelial neoplasia, AIS, adenocarcinoma in situ 


\section{Low-grade squamous intraepithelial lesion}

In low-grade squamous intraepithelial lesion (LSIL) cytology, the cells are of the superficial or intermediate cell types which have enlarged nuclei that are 4-6 times the size of a normal intermediate cell nucleus. The nuclei are usually hyperchromatic, and multinucleation is common However, in LSIL with marked HPV cytopathic changes, the nucleus are often only 2-3 times the size of a normal intermediate cell nucleus (Solomon and Nayar, 2004). In a region with a low incidence of cervical cancer, positive smear results for LSIL were associated with CIN2-3/AIS in approximately $12 \%-18 \%$ of women on initial colposcopy and with less than $1 \%$ of underlying invasive cancer (Massad et al., 2001; ALTS Group, 2003; Fairman et al., 2004; Chute et al., 2006). In Thailand, reported incidence of significant cervical pathology ranges from $11.2 \%$ to $32.2 \%$ (Table 2) (Khuakoonratt et al., 2008; Boonlikit, 2008; Kiatiyosnusorn et al., 2010; Ekalaksananan et al., 2011; Pothisuwan et al., 2011; Kingnate et al., 2014). The significant finding noted in some studies in Thailand is a relatively high incidence of underlying high-grade cervical lesion (11.2\%-30.3\%) and invasive lesion (1.3\%-1.9\%) (Khuakoonratt et al., 2008; Kiatiyosnusorn et al., 2010). Recommended management of LSIL cytology might be either colposcopy or cytological follow-up and varies between countries (Scheungraber et al., 2004). Nevertheless, immediate colposcopy might be appropriate in Thailand in which the patients' compliance is suboptimal (Rattanalappaiboon et al., 2014).

\section{High-grade squamous intraepithelial lesion}

High-grade squamous intraepithelial lesion (HSIL) cytology is acknowledged as a high-grade smear abnormality. The cytomorphologic features of squamous cells interpreting HSIL include an increased nuclear/ cytoplasmic ratio, marked atypical nucleus, and irregular nuclear border (Solomon and Nayar, 2004). Recommended management of women with HSIL cytology is either immediate colposcopy or immediate loop electrosurgical excision procedure (LEEP) after colposcopy, the socalled "see and treat" approach. Diagnostic cervical excision is advised if the colposcopic examination is inadequate, microinvasive carcinoma or low-grade lesion is identified on colposcopically-directed biopsy. Previous reported incidence of precancerous lesion and invasive cancer among population resided in low cervical cancer incidence areas ranges $60 \%-80 \%$ and $1-3 \%$, respectively (Jones and Davey, 2000; Massad et al., 2001; Szurkus and Harrison, 2003; Berdichevsky et al., 2004; Boman et al., 2004; Numnum et al., 2005; Chute et al., 2006; Sadan et al., 2007). In Thailand, although incidence of CIN2-3 and AIS in women with HSIL smears (62\% to $74 \%$ ) paralleled those reports of other populations, the incidences of underlying invasive disease were remarkably higher ranging from $7.9 \%$ to $25.8 \%$ (Kantathavorn et al., 2006; Boonlikit, 2008; Aue-Aungkul et al., 2011; Sripipattanakul, 2011; Ingkapairoj et al., 2012; Kingnate, et al., 2014) (Table 2). Therefore, intensive evaluation of Thai women with HSIL smears is mandatory in order to exclude occult invasive lesion.

\section{Squamous cell carcinoma cytology}

Squamous cell carcinoma (SCCA) cytology is sparse. In general, SCCA cytology could be subdivided into 2 categories including keratinizing and non-keratinizing types. In nonkeratinizing type, cells display most of the cytological characteristics of HSIL. Tumor diathesis is frequently present. In contrast, the pathognomonic feature of smear suggesting keratinizing squamous cell carcinoma is a marked variation in cellular size and shape. A tumor diathesis is usually less than that observed in nonkeratinizing type (Solomon and Nayar, 2004).

Table 2. Histopathological Outcome in Thai Women with Cervical Smears Revealing LSIL, HSIL and SCCA

\begin{tabular}{|c|c|c|c|c|c|c|}
\hline Authors & $\begin{array}{l}\text { Smear } \\
\text { type }\end{array}$ & Year & $\begin{array}{c}\text { No. } \\
\text { patients }\end{array}$ & CIN 1 or less & Underlying histopathology & Cancer \\
\hline & LSIL & & & & & \\
\hline Khuakoonrat et al & & 2008 & 226 & 189 (83.6) & $34(15.0)$ & $3(1.3)$ \\
\hline Boonlikit et al & & 2008 & 250 & $222(88.8)$ & $28(11.2)$ & $0(0)$ \\
\hline Kiatiyosnusorn et al & & 2010 & 208 & $141(67.8)$ & $63(30.3)$ & $4(1.9)$ \\
\hline Ekalaksananan et al & & 2011 & 78 & $68(87.2)$ & $10(12.8)$ & $0(0)$ \\
\hline Pothisuwan & & 2011 & 51 & $41(80.4)$ & $10(19.6)$ & $0(0)$ \\
\hline \multirow[t]{2}{*}{ Kingnate et al } & & 2014 & 395 & $315(79.8)$ & $76(19.2)$ & $4(1.0)$ \\
\hline & HSIL & & & & & \\
\hline Kantathavorn et al & & 2006 & 681 & $38(5.6)$ & $502(73.7)$ & $141(20.7)$ \\
\hline Boonlikit et al & & 2008 & 152 & $37(24.3)$ & $103(67.8)$ & $12(7.9)$ \\
\hline Sripipattanakut & & 2011 & 179 & $33(18.4)$ & $114(63.7)$ & $32(17.9)$ \\
\hline Aue-aungkul et al & & 2011 & 124 & $14(11.3)$ & $78(62.9)$ & $32(25.8)$ \\
\hline Ingkapairoj et al & & 2012 & 302 & $78(25.8)$ & $196(64.9)$ & $28(9.3)$ \\
\hline \multirow[t]{2}{*}{ Kingnate et al } & & 2014 & 143 & $36(25.2)$ & $89(62.2)$ & 18 (12.6) \\
\hline & SCCA & & & & & \\
\hline Charoenkwan et al & & 2006 & 48 & $1(2.1)$ & $31(64.6)$ & $16(33.3)$ \\
\hline Aue-aungkul et al & & 2011 & 9 & $0(0)$ & $4(44.4)$ & $5(55.6)$ \\
\hline Ruengkhachorn et al & & 2012 & 86 & $2(2.3)$ & $13(15.1)$ & $71(82.6)$ \\
\hline Kingnate et al & & 2014 & 31 & $2(6.5)$ & $5(16.1)$ & $24(77.4)$ \\
\hline
\end{tabular}

*LSIL, low-grade squamous intraepithelial lesion; HSIL, high-grade squamous intraepithelial lesion; SCCA, squamous cell carcinoma; CIN, cervical intraepithelial neoplasia, AIS, adenocarcinoma in situ 
Data regarding cervical pathology among women with SCCA cytology are limited due to the rarity of this smear abnormality. Two studies conducted in US population demonstrated approximately $15 \%-24 \%$ the risk of harboring invasive lesion in women with SCCA cytology (Jones adn Davey, 2000; Massad et al., 2001). These rates were much lower than those reported in the studies from Thailand. The study conducted in Chiang Mai reported that the incidence of significant cervical lesion in SCCA cytology was $98 \%$, in which $33.3 \%$ were invasive disease (Charoenkwan et al., 2006). Another study by Aue-aungkul et al (2011), in evaluating the clinical feasibility of the see and treat approach in managing Thai women with abnormal cervical cytology, from the same hospital reported that approximately $55.6 \%$ of women with SCCA cytology had invasive cervical lesions. An extraordinarily high incidence of underlying invasive lesion in women with SCCA cytology was concordantly found in recent reports from the other areas of Thailand by Ruengkhachorn et al (2012) and Kingnate et al (2014): $82.5 \%$ and $77.4 \%$ respectively. Thus, a high likelihood of harboring invasive disease in Thai women with SCCA smears should be kept in mind while taking care of women with SCCA cytology.

\section{Atypical glandular cells}

Screening for glandular disease of cervix remains among the major issues in gynecologic cytopathology. The 2001 Bethesda System has revised the reporting cervical smear interpreting glandular abnormality (Solomon and Nayar, 2004). This was in order to improve communication between laboratories and clinicians, indicate understanding of features of glandular neoplasia in cervical smear thereby result in appropriate approach for the patients.

A challenge in evaluating women with AGC bases on a wide variety of potential sites origin ranging from endocervix, endometrium, fallopian tube, ovary, and even of very rarely from extragenital sites. Per the 2001 Bethesda System, atypical glandular cells (AGC) is categorized according to the sites of origin (endocervical or endometrial) whenever feasible; otherwise, the generic "AGC" is used. Atypical endocervical cells may be further qualified as "favor neoplasia", if not so, "not otherwise specified (NOS) may be stated. Atypical endometrial cells are not recommended to be further qualified because of unreliable subcategorizing this category (Solomon and Nayar, 2004).

Initial management in women with AGC cytology consists of colposcopy and endocervical sampling. Additional endometrial sampling is recommended in women 35 years of age or older, and in women at risk of endometrial neoplasia. In the literature, the incidence of significant lesion in women with AGC-NOS varies from $5 \%$ to $33 \%$ (Haidopoulos et al., 2005; DeSimone et al., 2006; Behtash et al., 2007; Westin et al., 2008; Adhya et al., 2009; Schnatz et al., 2009; Zhao et al., 2009) as compared with $41 \%-70 \%$ in women with AGC-FN smears (Haidopoulos et al., 2005; DeSimone et al., 2006; Westin et al., 2008; Adhya et al., 2009; Schnatz et al., 2009). Extragenital malignant lesions were found in less than
$1 \%$ of women with AGC cytology (Zhao et al., 2009).

Four studies on the underlying lesions in women with AGC cytology conducted in Thailand were identified. Firstly, Sawangsang et al (2011) from Chiang Mai University Hospital reported that approximately $15 \%$ of women with AGC-NOS smears had significant lesions (CIN2-3, AIS, atypical endometrial hyperplasia, cancer), in which $2.2 \%$ were invasive lesions and all were cervical cancer. Of women with AGC-FN cytology, approximately $41.2 \%$ had significant lesions, in which, respectively, $17.6 \%$ and $5.9 \%$ were endometrial adenocarcinoma and cervical cancer.

Additional three studies were conducted in Bangkok. Lojindarat et al (2012) reported 32.4\% significant lesions in women with smear interpreting AGC, in which $18.3 \%$ were invasive lesion. Diagnoses of underlying significant lesion after AGC-FN were significantly more likely than those with AGC-NOS smears (53.8\% vs 20.0\%). Chatchotikawong et al (2012) reported that the likelihood of cancer precursor and malignant histologic results in the AGC-NOS group was $31.7 \%$ and $23.7 \%$, respectively, as compared with $65.4 \%$ and $55.1 \%$ of women in the AGC-FN group. An interested finding in this study was a relatively high incidence of extragenital malignant lesions (3.8\% of AGC-NOS and 5.1\% of AGC-FN smears) (Chatchotikawong et al., 2012). Recently, Kingnate et al (2014) observed that approximately $10.4 \%$ and $4.5 \%$ of women with AGC-NOS smears had CIN 2-3/AIS and invasive lesion, respectively. For women with AGC-FN, the incidence of significant lesion was $15 \%$ in which $5 \%$ were invasive lesion.

\section{Conclusion}

This review documents a relatively high rate of significant lesions particularly invasive disease among Thai women with abnormal cervical cytology screening even in those having only minimal smear abnormality. This baseline information must be taken into consideration in management of women with abnormal cytological screening to achieve the goals of comprehensive cervical cancer control in Thailand.

\section{References}

Adhya AK, Mahesha V, Srinivasan R, et al (2009). Atypical glandular cells in cervical smears: histological correlation and a suggested plan of management based on age of the patient in a low-resource setting. Cytopathology, 20,375-9.

Alli PM,Ali SZ (2003). Atypical squamous cells of undetermined significance-rule out high-grade squamous intraepithelial lesion: cytopathologic characteristics and clinical correlates. Diagn Cytopathol, 28, 308-12.

ASCUS-LSIL Triage Study (ALTS) Group (2003). A randomized trial on the management of low-grade squamous intraepithelial lesion cytology interpretations. Am J Obstet Gynecol, 188, 1393-400.

Aue-Aungkul A, Punyawatanasin S, Natprathan A, et al (2011). "See and treat" approach is appropriate in women with highgrade lesions on either cervical cytology or colposcopy. Asian Pac J Cancer Prev, 12, 1723-6.

Barreth D, Schepansky A, Capstick V, et al (2006). Atypical squamous cells-cannot exclude high-grade squamous 
intraepithelial lesion (ASC-H): a result not to be ignored. $J$ Obstet Gynaecol Can, 28, 1095-8.

Behtash N, Nazari Z, Fakhrejahani F, et al (2007). Clinical and histological significance of atypical glandular cell on Pap smear. Aust N Z J Obstet Gynaecol, 47, 46-9.

Berdichevsky L, Karmin R, Chuang L (2004). Treatment of highgrade squamous intraepithelial lesions: a 2- versus 3-step approach. Am J Obstet Gynecol, 190, 1424-6.

Boardman LA, Weitzen S, Stanko C (2006). Atypical squamous cells of undetermined significance, human papillomavirus, and cervical intraepithelial neoplasia 2 or 3 in adolescents: ASC-US, age, and high-grade cervical neoplasia. J Low Genit Tract Dis, 10, 140-5.

Boman F, Duhamel A, Trinh DQ, et al (2004). Histological diagnosis after Pap smears detecting cancer or high-grade lesion of the cervix. Gynecol Obstet Fertil, 32, 404-8.

Boonlikit S (2008). Prevalence of high-grade cervical lesion in women with LSIL and HSIL cytology and prevalence of invasive cancer in women cytologically positive for malignancy. Asian Pac J Cancer Prev, 9, 715-8.

Charoenkwan K, Srisomboon J, Suprasert P, et al (2006). Histopathological outcomes of women with squamous cell carcinoma on cervical cytology. Asian Pac J Cancer Prev, 7, 403-6.

Chatchotikawong U, Ruengkhachorn I,Laiwejpithaya S (2012). Factors predicting pathologic significance among women with atypical glandular cells on liquid-based cytology. Int $J$ Gynaecol Obstet, 119, 30-4.

Chute DJ, Covell J, Pambuccian SE, et al (2006). Cytologichistologic correlation of screening and diagnostic Papanicolaou tests. Diagn Cytopathol, 34, 503-6.

Cooke A, Smith D, Booth A (2012). Beyond PICO: the SPIDER tool for qualitative evidence synthesis. Qual Health Res, 22, 1435-43.

DeSimone CP, Day ME, Tovar MM, et al (2006). Rate of pathology from atypical glandular cell Pap tests classified by the Bethesda 2001 nomenclature. Obstet Gynecol, 107, 1285-91.

Ekalaksananan T, Pientong C, Kongyingyoes B, et al (2011). Combined p16INK4a and human papillomavirus testing improves the prediction of cervical intraepithelial neoplasia (CIN II-III) in Thai patients with low-grade cytological abnormalities. Asian Pac J Cancer Prev, 12, 1777-83.

Fairman A, Tan J, Quinn M (2004). Women with low-grade abnormalities on Pap smear should be referred for colposcopy. Aust N Z J Obstet Gynaecol, 44, 252-5.

Feng J, Husain M (2007). Outcomes of women with atypical squamous cells of undetermined significance and high-risk human papillomavirus DNA. Acta Cytol, 51, 730-4.

Haidopoulos DA, Stefanidis K, Rodolakis A, et al (2005). Histologic implications of Pap smears classified as atypical glandular cells. J Reprod Med, 50, 539-42.

Ingkapairoj N, Luanratanakorn S, Chumworathayi B, et al (2012). Incidences of cervical intraepithelial neoplasia 2-3 or cancer pathologic diagnoses in patients with a high grade squamous intraepithelial lesion pap smear attending a colposcopy clinic at srinagarind hospital. Asian Pac J Cancer Prev, 13, 6203-6.

Jones BA, Davey DD (2000). Quality management in gynecologic cytology using interlaboratory comparison. Arch Pathol Lab Med, 124, 672-81.

Kantathavorn N, Phongnarisorn C, Srisomboon J, et al (2006). Northern Thai women with high grade squamous intraepithelial lesion on cervical cytology have high prevalence of underlying invasive carcinoma. Asian Pac J Cancer Prev, 7, 477-9.

Kantathavorn N, Kietpeerakool C, Suprasert P, et al (2008).
Clinical relevance of atypical squamous cells of undetermined significance by the 2001 bethesda system: experience from a cervical cancer high incidence region. Asian Pac J Cancer Prev, 9, 785-8.

Khuakoonratt N, Tangjitgamol S, Manusirivithaya S, et al (2008). Prevalence of high grade squamous intraepithelial lesion (HSIL) and invasive cervical cancer in patients with low grade squamous intraepithelial lesion (LSIL) at cervical pap smear. Asian Pac J Cancer Prev, 9, 253-7.

Kiatiyosnusorn R, Suprasert P, Srisomboon J, et al (2010). Highgrade histologic lesions in women with low-grade squamous intraepithelial lesion cytology from a region of Thailand with a high incidence of cervical cancer. Int J Gynaecol Obstet, 110, 133-6.

Kiatpongsan S, Niruthisard S, Mutirangura A, et al (2006). Role of human papillomavirus DNA testing in management of women with atypical squamous cells of undetermined significance. Int J Gynecol Cancer, 16, 262-5.

Kietpeerakool C, Cheewakriangkrai C, Suprasert P, et al (2009). Feasibility of the 'see and treat' approach in management of women with 'atypical squamous cell, cannot exclude high-grade squamous intraepithelial lesion' smears.J Obstet Gynaecol Res, 35, 507-13.

Kingnate C, Tangjitgamol S, Khunarong J, et al (2014). Abnormal uterine cervical cytology in a large tertiary hospital in Bangkok metropolis: prevalence, management, and outcomes. Ind $J$ Cancer, [Epub ahead of print].

Levi AW, Kelly DP, Rosenthal DL, et al (2003). Atypical squamous cells of undetermined significance in liquid-based cytologic specimens: results of reflex human papillomavirus testing and histologic follow-up in routine practice with comparison of interpretive and probabilistic reporting methods. Cancer, 99, 191-7.

Liman AK, Giampoli EJ, Bonfiglio TA (2005). Should women with atypical squamous cells, cannot exclude high-grade squamous intraepithelial lesion, receive reflex human papillomavirus-DNA testing? Cancer, 105, 457-60.

Lojindarat S, Luengmettakul J, Puangsa-Art S (2012). Clinical significance of atypical glandular cells in cervical Papanicolaou smears. J Med Assoc Thai, 95, 975-82.

Louro AP, Roberson J, Eltoum I, et al (2003). Atypical squamous cells, cannot exclude high-grade squamous intraepithelial lesion. A follow-up study of conventional and liquid-based preparations in a high-risk population. Am J Clin Pathol, 120, 392-7.

Massad LS, Collins YC, Meyer PM (2001). Biopsy correlates of abnormal cervical cytology classified using the Bethesda system. Gynecol Oncol, 82, 516-22.

Massad LS, Einstein MH, Huh WK, et al (2013). 2012 updated consensus guidelines for the management of abnormal cervical cancer screening tests and cancer precursors. Obstet Gynecol, 121, 829-46.

McHale MT, Souther J, Elkas JC, et al (2007). Is atypical squamous cells that cannot exclude high-grade squamous intraepithelial lesion clinically significant? J Low Genit Tract Dis, 11, 86-9.

Moore MA, Attasara P, Khuhaprema T, et al (2010). Cancer epidemiology in mainland South-East Asia - past, present and future. Asian Pac J Cancer Prev, 11, 67-80.

Numnum TM, Kirby TO, Leath CA 3rd, et al (2005). A prospective evaluation of "see and treat" in women with HSIL Pap smear results: is this an appropriate strategy? $J$ Low Genit Tract Dis, 9, 2-6.

Poomtavorn Y, Suwannarurk K, Thaweekul Y, et al (2011). Risk factors for high-grade cervical intraepithelial neoplasia in patients with atypical squamous cells of undetermined significance (ASC-US) Papanicolaou smears. Asian Pac J 
Cancer Prev, 12, 235-8.

Pothisuwan M, Pataradool K, Tangjitgamol S, et al (2011). Visual inspection with acetic acid for detection of high grade lesion in atypical squamous cells and low grade squamous intraepithelial lesions from cervical Pap smear. J Gynecol Oncol, 22, 145-51.

Quddus MR, Sung CJ, Steinhoff MM, et al (2001). Atypical squamous metaplastic cells: reproducibility, outcome, and diagnostic features on ThinPrep Pap test. Cancer, 93, 16-22.

Rattanalappaiboon D, Kietpeerakool C, Kleebkaow P, et al (2014). Factors affecting compliance in the first year of postcolposcopy surveillance among women with a high incidence of cervical cancer. Int J Gynaecol Obstet, 124, 160-3.

Ruengkhachorn I, Laiwejpithaya S, Leelaphatanadit C, et al (2012). Clinicopathologic importance of women with squamous cell carcinoma cytology on Siriraj liquid-based cervical cytology. Asian Pac J Cancer Prev, 13, 4567-70.

Saad RS, Dabbs DJ, Kordunsky L, et al (2006). Clinical significance of cytologic diagnosis of atypical squamous cells, cannot exclude high grade, in perimenopausal and postmenopausal women. Am J Clin Pathol, 126, 381-8.

Sadan O, Yarden H, Schejter E, et al (2007). Treatment of highgrade squamous intraepithelial lesions: a "see and treat" versus a three-step approach. Eur J Obstet Gynecol Reprod Biol, 131, 73-5.

Safaeian M, Solomon D, Wacholder S, et al (2007). Risk of precancer and follow-up management strategies for women with human papillomavirus-negative atypical squamous cells of undetermined significance. Obstet Gynecol, 109, 1325-31.

Sawangsang P, Sae-Teng C, Suprasert P, et al (2011). Clinical significance of atypical glandular cells on Pap smears: experience from a region with a high incidence of cervical cancer. J Obstet Gynaecol Res, 37, 496-500.

Scheungraber C, Kleekamp N, Schneider A (2004). Management of low-grade squamous intraepithelial lesions of the uterine cervix. Br J Cancer, 90, 975-8.

Schnatz PF, Sharpless KE, O'Sullivan DM (2009). Use of human papillomavirus testing in the management of atypical glandular cells. J Low Genit Tract Dis, 13, 94-101.

Selvaggi SM (2003). Reporting of atypical squamous cells, cannot exclude a high-grade squamous intraepithelial lesion (ASC-H) on cervical samples: is it significant? Diagn Cytopathol, 29, 38-41.

Selvaggi SM (2006). ASC-US and high-risk HPV testing: performance in daily clinical practice. Diagn Cytopathol, 34, 731-3.

Sherman ME, Solomon D, Schiffman M (2001). Qualification of ASCUS. A comparison of equivocal LSIL and equivocal HSIL cervical cytology in the ASCUS LSIL Triage Study. Am J Clin Pathol, 116, 386-94

Sherman ME, Castle PE, Solomon D (2006). Cervical cytology of atypical squamous cells-cannot exclude high-grade squamous intraepithelial lesion (ASC-H): characteristics and histologic outcomes. Cancer, 108, 298-305.

Siddiqui MT, Hornaman K, Cohen C, et al (2008). ProEx C immunocytochemistry and high-risk human papillomavirus DNA testing in papanicolaou tests with atypical squamous cell (ASC-US) cytology: correlation study with histologic biopsy. Arch Pathol Lab Med, 132, 1648-52.

Solomon D, Nayar R (2004). The Bethesda system for reporting cervical cytology (second ed.). New York: Springer-Verlage.

Sripipattanakul M (2011). The see and treat approach in women with high-grade squamous intraepthelial lesion on Pap smear. Khon Kaen Med J, 35, 30-5.

Srodon M, Parry Dilworth H, Ronnett BM (2006). Atypical squamous cells, cannot exclude high-grade squamous intraepithelial lesion: diagnostic performance, human papillomavirus testing, and follow-up results. Cancer, $\mathbf{1 0 8}$, 32-8.

Suntornlimsiri W (2010). Women in a region with high incidence of cervical cancer warrant immediate colposcopy for atypical squamous cells of undetermined significance on cervical cytology. J Med Assoc Thai, 93, 676-681.

Szurkus DC, Harrison TA (2003). Loop excision for high-grade squamous intraepithelial lesion on cytology: correlation with colposcopic and histologic findings. Am J Obstet Gynecol, 188, 1180-2.

Westin MC, Derchain SF, Rabelo-Santos SH, et al (2008). Atypical glandular cells and adenocarcinoma in situ according to the Bethesda 2001 classification: cytohistological correlation and clinical implications. Eur J Obstet Gynecol Reprod Biol, 139, 79-85.

Zhao C, Florea A, Onisko A, et al (2009). Histologic follow-up results in 662 patients with Pap test findings of atypical glandular cells: results from a large academic womens hospital laboratory employing sensitive screening methods. Gynecol Oncol, 114, 383-9. 